\title{
Attitude and Cognitive Distortion on HIV/AIDS among Undergraduate Students of Madda Walabu University, Southeast Ethiopia
}

Abera Getachew $^{1 *}$ and Gobena Daniel ${ }^{2}$

${ }^{1}$ Institute of Education and Behavioural Sciences, Ambo University, West Showa, Oromia, Ethiopia

${ }^{2} S c h o o l$ of Psychology, College of Education and Behavioural Sciences, Addis Ababa University, Ethiopia

\begin{abstract}
Introduction: Worldwide over half of all new infections are among young people. The primary prevention and control of the spread of HIVIAIDS infection is through awareness and changing behaviour remains at the highest priority. The aim of the study was to assess the attitude and cognitive distortion towards HIVIAIDS among undergraduate students of Madda Walabu University Southeast Ethiopia.
\end{abstract}

Methods: Cross sectional study with quantitative methods of data collection was employed among 605 randomly selected under graduate regular students in March, 2014. Data were collected using self-administering questionnaire. The analysis employed using SPSS version 20 to calculate t-test and ANOVA.

Result: The average number of students of Madda Walabu University who had poor attitude on sexual abstinence241 (39.8\%), mutual monogamy $274(45.3 \%)$, use of condom $227(37.5 \%)$ and towards people living with HIV. The ANOVA psychological-cognitive distortion of the study participants had statistically significant difference among students age $[F(6,594)=2.134, P<0.05]$ and academic year level $[F(6,598)=2.471, p<0.05]$ on their total score of all-or- nothing thinking. Statistical significant difference was also observed between age and overgeneralization thinking of participants, $F(6,594)=2.619, p<0.05$ and residential status, $F(6,593)=3.646, p<0.01$. Similarly, age of the students has a statistical significant effect on mental filtration, $F(6,594=2.399, p<0.05)$. One sample t-test showed $t$-value for abstinence $(t=-1.096$, mutual monogamy $d f=604,<0.05)$ and condom use $(t=-283, d f=604, p<0.05)$ was less than the critical t-value at 0.05 level.

Conclusion: Socio-demographic variables such as age, sex, academic year level, admission type, had significant effect on cognitive distortions or dysfunctional belief about sexual abstinence, mutual monogamy and condom use. Students indicate unfavourable attitude towards those infected with HIVIAIDS. HIVIAIDS counselling, health education and intervention strategies must focus on behavioural changes, safer sex and changing the negative attitude towards HIVIAIDS.

Keywords: HIV/AIDS; Attitude; Cognitive distortion; University students

\section{Introduction}

HIV/AIDS is continuing to be a world challenge. Young people are the most affected groups that include university under graduate students as well. One of the main negative outcomes for people with symptoms of HIV is stigmatizing attitudes. Stigma and discrimination associated with HIV/AIDS are the biggest challenges experienced by people suffering from the disease and it has been recognized as a serious threat to the fundamental rights of all infected people who are affected by or associated with this disease. Those aged 15-24 years accounted for $42 \%$ of new HIV infections and nearly $80 \%$ of this lives in sub-Saharan Africa including Ethiopia [1-4].

There are anecdotes and reports that indicate that HIV/AIDS has had a significant impact on higher education institutions. The epidemic has affected students, their lecturers and non-teaching staff. The University environment provides unique challenges to the students, lecturers and communities. University environment expose learners for multiple sex partnerships, unprotected sex, transactional sex, cross-generational sex and sex for favours such as marks in exams. As consequence university students are more likely to have sex with high-risk partners or multiple partners [5]. Self-efficacy, outcome expectancies and perception of peer attitudes at the beginning of sexual activity also can affect the use of condoms among young people who are sexually active [6].

There has been idea among students that those infected with HIV should be separated from their communities and keep away from those infected. In line with this statement, most people develop negative attitude towards PLWHA because most people share the same reasoning and perception towards people living with HIV/AIDS. As a result it is critical for HIV/AIDS prevention and control program to have the relevant information regarding tertiary students' attitudes toward people with AIDS, students' beliefs about AIDS in relationship to themselves [7].

Notwithstanding all the efforts by both government and nongovernmental organization against AIDS, the problem of the pandemic is still at increase. Therefore in looking at the problem of attitude and cognitive distortion on HIV/AIDS among undergraduate students is very crucial.But there is dearth information among undergraduate students of Ethiopia specifically the study area. As a result this study assessed attitude and cognitive distortion towards HIV/AIDS among undergraduate students of Madda Walabu University Southeast Ethiopia.

*Corresponding author: Abera Getachew, Department of Psychology, Institute of Education and Behavioural Sciences, Ambo University, West Shewa, Oromia Ethiopia, Tel: +251922856525; E-mail: abegeta12@gmail.com

Received October 07, 2016; Accepted October 25, 2016; Published November 02, 2016

Citation: Getachew A, Daniel G (2016) Attitude and Cognitive Distortion on HIV/ AIDS among Undergraduate Students of Madda Walabu University, Southeast Ethiopia. J AIDS Clin Res 7: 630. doi: 10.4172/2155-6113.1000630

Copyright: (c) 2016 Getachew A, et al. This is an open-access article distributed under the terms of the Creative Commons Attribution License, which permits unrestricted use, distribution, and reproduction in any medium, provided the original author and source are credited. 


\section{Methods}

\section{Study design and area}

Institutional-based cross-sectional study was conducted among 605 randomly selected regular undergraduate students in March, 2014 of Madda Walabu University in Ethiopia and located at a distance of 430 $\mathrm{km}$ to the Southeast of Addis Ababa. The university has two campuses, Robe main campus and Goba College of Medicine and Health Sciences. In the year 2014 the university has ten schools, one institute, one college and thirty seven departments with the total number of 5,960 undergraduate students.

\section{Sampling and participants}

Regular undergraduate students of Madda Walabu University were the source population and the study populations were those selected students for study through simple random sampling. The sample size was determined by using a single population proportion formula considering the assumptions: proportion of self-efficacy which was $59.8 \%$ [8] level of confidence of $95 \%$, margin of error 0.05 , design effect of 1.5 and $10 \%$ non-response rate were considered. Finally the sample size was 609 .

The respondents were stratified into health and non-health campus. From the total ten non-health schools (Robe campus) and one medicine and health sciences college of the university (Goba campus), eight schools/college were selected randomly. The total sample size of the study was allocated proportionally for the schools/college. Sample allocated for the schools/college were allocated proportionally for the stratified class year under the departments of selected schools/college. Finally, simple random sampling was employed to reach 605 the study subject.

\section{Data collection and analysis}

In order to collect the relevant and reliable data the researcher employed the close ended questionnaire used from the tools used before by scholars in the area. Data were collected through self-administered questionnaire. Before data entry questionnaires were checked for completeness and entry was made SPSS windows version 16 for analysis. Accordingly, Percentage, t-test and ANOVA were computed and results were presented by tables. Association between the explanatory and dependent variable were assessed at p-value of 0.05 .

This study is not free of limitations. Since the study was conducted in relatively small and geographically restricted area, the result of this study finding was compromised to some extent to accurately represent the negative attitude and cognitive distortion problem occurred towards PLWHA in Ethiopian higher education institution. Also the study involves only quantitative method of data collection, the level of attitude and cognitive distortion was being under-reported.

\section{Results}

\section{Socio-demographic characteristics of the respondents}

From the total 609 participants, 605 of them responded to the questionnaires that produce a response rate of $99.3 \%$. Three fourth 452 (74.7\%) of the participants were male. Majority of the study participant aged below 25 years and more than half 353 (58.3\%) of the respondents age ranged from 21-25 years. Regarding their origin of residence 361 (59.7\%) them were from rural community. Moreover, academic year level, $244(40.3 \%)$ and 203 (33.5\%) of them were year I and year II, respectively (Table 1).

\section{Attitude of students towards HIV/AIDS}

The attitude of study participant toward HIV/AIDS was negative. The $\mathrm{t}$-value for attitude on HIV and AIDS total score $(\mathrm{t}=5.826, \mathrm{df}=604$, $\mathrm{p}<0.001$ ) was less than the critical $t$-value at 0.05 level of significant. This shows that there is statistical significant difference between the observed sample mean for total score and attitude on HIV and AIDS (22.97) and the expected mean (24.00).

Regarding feelings of respondents toward HIV/AIDS prevention and control strategies, more than one third 241 (39.8\%) of the students agreethat sexual abstinence was very difficult while 216 (35.7\%) of them students agreed abstinencewas easier said than done. In terms of mutual monogamy, $274(45.3 \%)$ of the students agreed with the ideas of being faithful to one's partner is meaningless since the other partner may cheat. Moreover, they also agreed that it is unlikely that two people would be faithful to each other always, $211(34.9 \%)$ and hopeless to be fully faithful, $221(36.5 \%)$. In relation to correct and consistent use of condom 227 (37.5\%) of the respondents agreed that using condom kill sex play, while 208 (34.4\%) and 179 (29.6\%) agreed with false perception of sensory and poor decision of joy respectively (Table 2).

\section{The relationship between attitude toward HIV/AIDS and} some selected socio-demographic variable

Socio-demographic variables namely admission type, sex and age had statistically significant difference on attitude toward HIV/AIDS with reference abstinence and mutual monogamy. Admission type of the participants hadsignificant effect on the difficulty of sexual abstinence, $\mathrm{F}(1,603)=5.4, \mathrm{p}<0.05$. There was also statistically significance difference on difficulty of sexual abstinence across sex, $\mathrm{F}(1,603)=8.97, \mathrm{p}<0.01$ and age, $\mathrm{F}(3,595)=6.2, \mathrm{p}<0.01$ respectively. Moreover, age of the participants had statistically significant effect on number of the participants able to abstinence, $\mathrm{F}(3,595)=1.82, \mathrm{p}<0.01$, while the sex was observed significant, $\mathrm{F}(1,603)=7.3, \mathrm{p}<0.01$, on practice of abstinence. Finally, age of the participants had a significant effect on poor decision on faithfulness, $\mathrm{F}(3,595)=2.68, \mathrm{p}<0.05$ (Table 3 ).

\section{HIV/AIDS cognitive distortion of students}

Psychological-cognitive distortions were varies across age, academic year level, residential status, sex and admission type of the participants of this study. The psychological-cognitive distortion of the study participants had statistically significant difference among students age $[\mathrm{F}(6,594)=2.134, \mathrm{P}<0.05]$ and academic year level $[\mathrm{F}$

\begin{tabular}{|c|c|c|c|}
\hline \multirow{2}{*}{ Sex } & & $\mathbf{N}$ & $\%$ \\
\hline \multirow{2}{*}{ Admission Type } & Male & 452 & 74.7 \\
\cline { 2 - 4 } & Female & 153 & 25.3 \\
\hline \multirow{2}{*}{ Residential status } & Regular & 523 & 86.4 \\
\cline { 2 - 4 } & Extension & 82 & 13.6 \\
\cline { 2 - 4 } & Urban & 239 & 39.5 \\
\hline \multirow{3}{*}{ Age } & Rural & 361 & 59.7 \\
\cline { 2 - 4 } & $18-20$ & 194 & 32.1 \\
\cline { 2 - 4 } & $21-25$ & 353 & 58.3 \\
\cline { 2 - 4 } & $26-30$ & 47 & 7.8 \\
\hline \multirow{3}{*}{ Year of study } & $31-35$ & 11 & 1.8 \\
\cline { 2 - 4 } & I & 244 & 30.3 \\
\cline { 2 - 4 } & II & 203 & 22.7 \\
\hline
\end{tabular}

Table 1: Socio-demographic variables of under graduate regular students of Madda Walabu University, March, 2014. 
Citation: Getachew A, Daniel G (2016) Attitude and Cognitive Distortion on HIVIAIDS among Undergraduate Students of Madda Walabu University, Southeast Ethiopia. J AIDS Clin Res 7: 630. doi: 10.4172/2155-6113.1000630

Page 3 of 6

$(6,598)=2.471, \mathrm{p}<0.05]$ on their total score of all-or-nothing thinking. Statistical significant difference was also observed between age and overgeneralization thinking of participants, $F(6,594)=2.619, \mathrm{p}<0.05$ and residential status, $F(6,593)=3.646, \mathrm{p}<0.01$. Similarly, age of the students has a statistical significant effect on mental filtration, $\mathrm{F}$ $(6,594=2.399, p<0.05$. In contrary, there is no statistical significant difference, $\mathrm{F}(6,593)=1.748, \mathrm{p}>0.05$ between students of urban and rural resident on the mental filtration.

Moreover, the result shows that there was statistical significant difference between frequency of disqualifying positive thought and sex of the respondents, $\mathrm{F}(6,598)=2.704, \mathrm{p}<0.01$. On the other hand, the $\mathrm{F}$ $(6,598)=3.081, \mathrm{p}<0.01$ and, $\mathrm{F}(7.597)=2.717, \mathrm{p}<0.01$ elaborate that there was significant difference between admission type of the students on the cognitive distortion variables (magnification and minimization, and emotional reasoning)respectively.The analysis also shows, there was statistically significant difference between the frequency of making should statements and academic year level, $F(7,597)=2.556, p<0.01$. Finally, as it can be seen from the table above ,the result of this study revealed that statistical significant difference effect was reported between residential status of the study participants and making should statements, $\mathrm{F}(7,592)=2.392, \mathrm{p}<0.05$ and, labelling, $\mathrm{F}(7,593)=3.334$, $\mathrm{p}<0.01$ (Table 4).
With regard to cognitive distortions on HIV and AIDS there was significant difference between the observed sample mean for abstinence and condom use (19.80 and 19.95) the expected mean (20) of the students' response to those variables. One sample t-test showed $\mathrm{t}$-value for abstinence $(\mathrm{t}=-1.096$, mutual monogamy $\mathrm{df}=604,<0.05)$ and condom use $(\mathrm{t}=-283, \mathrm{df}=604, \mathrm{p}<0.05)$ was less than the critical $\mathrm{t}$-value at 0.05 level of significance. Hence, as the sample means significantly less than the expected mean, it can be reported that students have cognitive distortion on HIV and AIDS in relation to abstain and condom use. Independent sample t-test for cognitive distortion on HIV/AIDS related to abstinence showed that there was no statistically significant difference based on students admission type, $\mathrm{t}(603)=-1.24, \mathrm{p}>0.05$.

\section{Discussion}

The analysis of socio-demographic variables of this study indicates that majority of the students $74.7 \%$ were male and age ranges from 21-25 were comprises $58.3 \%$. In addition, relatively large number of student's resident of rural (59.7\%).The finding also indicates that most of the students (40.3\%) were first year in academic year level. Finally the majority, $86.4 \%$ of the students was following their regular program. As with other studies conducted in China university students in different cultures, attitude on HIV and AIDS were varies across sex, residential

\section{Abstinence}

Sexual abstinence is very difficult

Very few young people would be strong enough to abstain from sex till marriage.

Abstinence is easier said than done.

\section{Be faithful}

Being faithful to one's partner is meaningless since the other partner may cheat.

It is unlikely that two people would be faithful to each other always.

It is rather too naïve to expect one's partner to be fully faithful.

\begin{tabular}{|c|c|c|c|c|c|c|c|}
\multicolumn{2}{c|}{ Agree } & \multicolumn{2}{c|}{ Disagree } & \multicolumn{2}{c|}{ Not sure } & Total & \\
\hline $\mathbf{N}$ & $\%$ & $\mathbf{n}$ & $\%$ & $\mathbf{n}$ & $\%$ & Total & $\%$ \\
\hline 241 & 39.8 & 212 & 35 & 152 & 25.1 & 605 & 100 \\
\hline 195 & 32.2 & 251 & 41.5 & 159 & 26.3 & 605 & 100 \\
\hline 216 & 35.7 & 203 & 33.6 & 186 & 30.7 & 605 & 100 \\
\hline
\end{tabular}

Correct and consistent condom use

\begin{tabular}{|c|c|c|c|c|c|c|c|c|}
\hline Using condoms kills sex play. & 227 & 37.5 & 139 & 23 & 239 & 39.5 & 605 & 100 \\
\hline The sensory aspects (smell, touch, etc.) of condoms make them unpleasant. & 179 & 29.6 & 171 & 28.3 & 225 & 42.1 & 605 & 100 \\
\hline It is unthinkable to fully enjoy sex while using condom. & 208 & 34.4 & 152 & 25.1 & 245 & 40.5 & 605 & 100 \\
\hline
\end{tabular}

Table 2: The attitude of Madda Walabu University undergraduate students on HIV and AIDS prevention and control strategies, March, 2014.

\begin{tabular}{|c|c|c|c|c|c|c|}
\hline HIV positive people & leserve & SS & df & MS & $\mathbf{F}$ & $\mathbf{P}$ \\
\hline \multirow{3}{*}{ Admission type } & Between groups & 3.43 & 1 & 3.43 & 5.4 & \multirow{3}{*}{$0.02^{* *}$} \\
\hline & Within groups & 380.52 & 603 & 0.63 & & \\
\hline & Total & 383.96 & 604 & & & \\
\hline \multicolumn{7}{|c|}{ Sexual abstinence is difficult } \\
\hline \multirow{3}{*}{ Sex } & Between groups & 6.62 & 1 & 6.62 & 8.97 & \multirow{3}{*}{$0.00^{* *}$} \\
\hline & Within groups & 444.98 & 603 & 0.73 & & \\
\hline & Total & 451.61 & 604 & & & \\
\hline \multicolumn{7}{|c|}{ Sexual abstinence is difficult } \\
\hline \multirow{3}{*}{ Age } & Between groups & 13.56 & 3 & 4.52 & 6.2 & $0.00^{* *}$ \\
\hline & Within groups & 434.02 & 595 & 4.72 & & \\
\hline & Total & 447.59 & 598 & & & \\
\hline \multicolumn{7}{|c|}{ Few people could abstain } \\
\hline \multirow{3}{*}{ Sex } & Between groups & 5.01 & 1 & 5.01 & 7.3 & \multirow{3}{*}{$0.00^{* *}$} \\
\hline & Within groups & 413.7 & 603 & 0.68 & & \\
\hline & Total & 418.72 & 604 & & & \\
\hline \multicolumn{7}{|c|}{ Faithfulness is meaningless because the other partner may cheat } \\
\hline \multirow{3}{*}{ Age } & Between groups & 5.12 & 3 & 1.7 & 2.68 & $0.04^{*}$ \\
\hline & Within groups & 378.09 & 595 & 0.63 & & \\
\hline & Total & 383.21 & 598 & & & \\
\hline
\end{tabular}

Table 3: ANOVA results on attitude on HIV and AIDS by admission type, sex and age of the students, March, 2014. 
Citation: Getachew A, Daniel G (2016) Attitude and Cognitive Distortion on HIVIAIDS among Undergraduate Students of Madda Walabu University, Southeast Ethiopia. J AIDS Clin Res 7: 630. doi: 10.4172/2155-6113.1000630

Page 4 of 6

\begin{tabular}{|c|c|c|c|c|c|c|}
\hline \multicolumn{2}{|c|}{ 1. All or Nothing Thinking } & SS & MS & $\mathbf{F}$ & df & $\mathbf{P}$ \\
\hline \multirow{3}{*}{ Age } & Between & 5.339 & 0.89 & 2.134 & 6 & $0.04^{*}$ \\
\hline & Within & 247.663 & 0.417 & & 594 & \\
\hline & Total & 253.002 & & & 600 & \\
\hline \multirow{3}{*}{ Academic Year Level } & Between & 10.876 & 1.813 & & 6 & $0.02^{*}$ \\
\hline & Within & 438.704 & 0.734 & 2.471 & 598 & \\
\hline & Total & 449.58 & & & 604 & \\
\hline \multicolumn{7}{|l|}{ 2. Over Generalization } \\
\hline \multirow{3}{*}{ Age } & Between & 6.522 & 1.087 & 2.619 & 6 & $0.01^{*}$ \\
\hline & Within & 246.48 & 0.415 & & 594 & \\
\hline & Total & 253.002 & & & 600 & \\
\hline \multirow{3}{*}{ Residential status } & Between & 5.116 & 0.853 & & 6 & $0.00^{* *}$ \\
\hline & Within & 138.682 & 0.234 & 3.646 & 593 & \\
\hline & Total & 143.798 & & & 599 & \\
\hline \multicolumn{7}{|l|}{ 3. Mental Filtration } \\
\hline \multirow{3}{*}{ Age } & Between & 5.986 & 0.998 & 2.399 & 6 & $0.02^{*}$ \\
\hline & Within & 247.016 & 0.416 & & 594 & \\
\hline & Total & 253.002 & & & 600 & \\
\hline \multirow{3}{*}{ Residential status } & Between & 2.5 & 0.417 & 1.748 & 6 & $0.10^{* *}$ \\
\hline & Within & 141.299 & 0.238 & & 593 & \\
\hline & Total & 143.798 & & & 599 & \\
\hline \multicolumn{7}{|c|}{ 4. Disqualifying the Positive } \\
\hline \multirow{3}{*}{ Sex of Respondents } & Between & 3.274 & 0.546 & & 6 & $0.01^{*}$ \\
\hline & Within & 120.683 & 0.202 & 2.704 & 598 & \\
\hline & Total & 123.957 & & & 604 & \\
\hline \multicolumn{7}{|c|}{ 5. Jumping to conclusion } \\
\hline \multirow{3}{*}{ Residential status } & Between & 4.692 & 0.782 & 3.334 & 6 & $0.00^{* *}$ \\
\hline & Within & 139.106 & 0.235 & & 593 & \\
\hline & Total & 143.798 & & & 599 & \\
\hline \multicolumn{7}{|c|}{ 6. Magnification and Minimization } \\
\hline \multirow{3}{*}{ Admission type } & Between & 2.125 & 0.354 & & 6 & $0.00^{* *}$ \\
\hline & Within & 68.761 & 0.115 & 3.081 & 598 & \\
\hline & Total & 70.886 & & & 604 & \\
\hline \multicolumn{7}{|l|}{ 7. Emotional Reasoning } \\
\hline \multirow{3}{*}{ Admission type } & Between & 2.188 & 0.313 & & 7 & $0.00^{* *}$ \\
\hline & Within & 68.698 & 0.115 & 2.717 & 597 & \\
\hline & Total & 70.886 & & & 604 & \\
\hline \multicolumn{7}{|c|}{ 8. Making Should Statement } \\
\hline \multirow{3}{*}{ Academic Year Level } & Between & 13.08 & 1.869 & 2.556 & 7 & $0.01^{*}$ \\
\hline & Within & 436.501 & 0.731 & & 597 & \\
\hline & Total & 449.58 & & & 604 & \\
\hline \multirow{3}{*}{ Residential status } & Between & 3.956 & 0.565 & 2.392 & 7 & $0.02^{* *}$ \\
\hline & Within & 139.843 & 0.236 & & 592 & \\
\hline & Total & 143.798 & & & 599 & \\
\hline Labeling & & & & & & \\
\hline & Between & 4.692 & 0.782 & 3.334 & 6 & $0.00^{* *}$ \\
\hline Residential status & Within & 139.106 & 0.235 & & 593 & \\
\hline & Total & 143.798 & & & 599 & \\
\hline Personalization & & & & & & \\
\hline & Between & 3.143 & 0.449 & 1.89 & 7 & 0.06 \\
\hline Residential status & Within & 140.655 & 0.238 & & 592 & \\
\hline & Total & 143.798 & & & 599 & \\
\hline
\end{tabular}

${ }^{*} p<0.05,{ }^{* *} p<0.01$

Table 4: ANOVA results on distribution of HIVIAIDS cognitive distortion of students by sex, age and academic year level, March, 2014.

status and academic year levels of the students. This study also identifies the significant difference of residential status towards stigmatizing and discriminating the HIV patients. In relation to this many people living with HIV/AIDS are afraid to tell anyone about their status. If they choose to tell people in their surroundings they risk losing their social support and job being discriminated against in other ways [9].
The result of this finding revealed that mutual monogamy is difficult due to personal attitudes towards each other. The study also shows, relatively high number of respondents agreed consistent and correct condom use kills sex play bad sensory perception and poor decision of joy. Our analysis showed relatively low percentage (33.5\%). The findings of this study are inconsistent with that of china that, $54 \%$ of the 
participants felt that persons with HIV/AIDS deserve it. As this finding we can conclude that, average number of students of Madda Walabu University had poor attitude on sexual abstinence, mutual monogamy, use of condom and towards people living with HIV/AIDS.

Cognitive theory and research has indicted that cognitive distortions contributes to psychological and behavioural disorders [10]. The ANOVA finding of this study suggested that age of the respondents had a significant effect on cognitive distortion -all-or-nothing thinking, mental filtration, over generalizing thinking. This implies that, negative thinking towards sexual abstain, mutual monogamy and condom use varies across age of the respondents.

The result also showed the significance of academic year level on all-or-nothing thinking, making should statement and admission type on perceiving something too much or less important than it is and predominant use of emotional state in forming the conclusion on sexual intercourse.

Furthermore, the finding revealed the significance of sex and admission type on the cognitive distortion the value of altering cognitive distortions is reinforced a body of research suggesting that the influencing of negative life events on subject in feelings is far more powerful than that of positive life events [11].

As clearly, stated in the result section of this study, one third of the respondents reported the negative assumptions about sexual abstinence, mutual monogamy and condom use. This implies the underlying of cognitive distortion among the respondents. During on the theoretical assumption that individual with fewer cognitive distortions are less likely to become depressed in response to negative events. Depressed clients, who received CT, have demonstrated lower rate of cognitive distortion thoughts. Successful treatment of the emotional disorders involving cognitive restructuring through the identification, evaluation and responses to a client's cognitive distortions and dysfunctional beliefs $[12,13]$.

The finding of the study suggested admission types and level of education had a significant effect on enacting - abstinence both on confidence not to make premarital sex and ability to delay sex till marriage. Academic year level had also significant effect on correctly and consistently use of condom. This is consistent with the findings of Ministry of Health which depicts respondents with a higher level of schooling were aware of various preventive methods [14]. Sexual risk behaviour can be avoided by limiting the number of sexual partners, delaying individual sexual debut and having protected sex is curtail in the prevention and control of HIV/AIDS. In line with these explanations, our result showed a significant difference between male and female in pass challenging situation in remaining mutual monogamy in the absence of each partner [15]. This difference might be because of biological differences between male and female.

According to Malindwa, there are different social; and individual reasons (barriers) that may contribute to low level of condom use, knowing what condom is, from where to get it and how to use it correctly, can be taken as factors that increase self-efficacy towards use of condom by an individual [16]. This shows that males and female adolescents share similar attitude towards AIDS. From the calculations; it is observed that both share negative attitude towards AIDS. This is an indication that little or nothing have been done to change the negative attitude of public particularly adolescents towards AIDS. Most adolescents still believe that AIDS is rumour especially some that resides in the rural area. Some of them about 30\% do not know the meaning of HIV or AIDS while other sees it as a curse. Majority of them vowed not to have anything in common with any individual living with the virus. This negative attitude promotes stigmatization against people living with HIV/AIDS. While microscopic few individual adolescents share positive attitude to AIDS and those living with the virus, majority show discriminative attitude towards it.

However, the issue of negative attitude towards AIDS and PLWHA has become a global problem. In Hong Kong also reported high level of discriminatory attitude towards HIV/AIDS and PLWHA among adolescents [17]. This indicates that urban and rural adolescents differ significantly on their attitude towards AIDS. In other words, adolescents who live in the rural area do not share the same attitude with those who live in the urban area toward AIDS.

The statistical mean indicates that adolescents who live in the rural area show higher negative attitude towards AIDS than those who live in the urban area. Though the normative mean indicates that both urban and rural adolescents have negative attitude towards AIDS, it went further to reveal that it is very high among those who live in the rural area. The reason for this may be attributed to various factors such as illiteracy, lack of proper knowledge about HIV/AIDS, belief system, cultural factors and so on. Most of the adolescents in the rural areas were illiterates. Majority of them ended their education at primary school while others were drop out from secondary school. This affects their sense of reality and general knowledge about AIDS. In addition most belief that AIDS is a curse, others say that there is nothing like AIDS.

AIDS is an important public health problem because the complex, emotional, behavioural, and psychosocial complication that accompany the physical illness. The best single way to prevent the disease is through education [18-20]. Prevention of HIV/AIDS infection through continuing education is a key strategy for the control of the HIV/AIDS epidemic at least until vaccines and drugs are available, accessible and affordable.

In order to restrict the AIDS pandemic, it is crucial to induce changes not only in awareness and attitudes, but also behaviour which would reduce the possibility of HIV/AIDS infection [21]. Nineteen present of students in a study in Israel had the attitude that HIVpositive students should not be allowed to continue their studies as they can endanger their fellow students [22].

\section{Conclusion and Recommendation}

The undergraduate students are particularly vulnerable to HIV/ AIDS due to their age group which constitutes the peak period for sexual activity. Majority of the students had negative attitudes towards the three HIV/AIDS prevention and control methods (mutual monogamy, sexual abstinence and consistent and correct condom use). Sociodemographic variables such as age, sex, academic year level, admission type, had significant effect on cognitive distortions or dysfunctional belief about sexual abstinence, mutual monogamy and condom use. Perhaps the most encouraging fact was that students overall show a considerate and compassionate attitude towards those infected. Students also indicate a positive and healthy attitude towards those infected with HIV/AIDS, which could be due to accurate knowledge of this disease.

HIV/AIDS counselling, health education and intervention strategies must focus on behavioural changes and negative attitudes towards HIV/AIDS. Madda Walabu University should offer health education program related to HIV/AIDS prevention among their students. Beside health education, intervention strategies must focus 
Citation: Getachew A, Daniel G (2016) Attitude and Cognitive Distortion on HIVIAIDS among Undergraduate Students of Madda Walabu University, Southeast Ethiopia. J AIDS Clin Res 7: 630. doi: 10.4172/2155-6113.1000630

on behavioural changes towards safer sex, and changing the negative attitude towards HIV/AIDS and those infected with HIV.

\section{Authors' Contribution}

AG and GD conceived and designed the study. AG and GD were involved in the conception. AG analysed the data. AG prepared the manuscript. AG critically reviewed the manuscript. AG and GD assisted in the data collection and reviewed the manuscript. All authors have read and approved the final manuscript.

\section{References}

1. UNAIDS, WHO (2009) AIDS epidemic updates. Geneva.

2. FHI, USAID, Youth Net Assessment Team (2012) Assessment of youth reproductive health programs in Ethiopia 2012, Addis Ababa, Ethiopia.

3. World Bank, MOE (2014) Profile on higher education at first degree level, Ethiopia.

4. Holzemer WL, Uys L, Makoae L, Stewart A, Phetlhu R, et al. (2007) A conceptual model of HIVIAIDS stigma from five African countries. J Adv Nurs 58: 541-551.

5. Central Statistics Authority (1988) Population projection of Ethiopia: Total and sectorian (1985-2035). Population Studies, Ethiopia.

6. Dilorio C, Dudley WN, Kelly M, Soet JE, Mbwara J, et al. (2001) Social cognitive correlates of sexual experience and condom use among 13 through 15 year old adolescents. Journal of Adolescents Health 29: 208-216.

7. Jose O, Totona K, Begani A, Andew T, Tombe B, et al. (2011) Knowledge attitudes and beliefs on HIVIAIDS among tertiary students in Papua, New Guinea. World Journal of AIDS 1: 50-61.

8. Al-Rabeei NA, Dallak AM, Al-Awadi FG (2012) Knowledge, attitude and beliefs towards HIVIAIDS among students of health institutes in Sana'a city. East Mediterr Health J 18: 221-226.

9. Zhang K, Beck EJ (1999) Changing sexual attitudes and behavior in china: Implications for the read of HIV and other sexually transmitted disease. AIDS Care 11: 581-589.
10. Beck AT, Freeman A, Davis DD (2004) Cognitive therapy of personality disorders ( $2^{\text {nd }}$ edn) Guilford Press, New York

11. Larsen RK, Prizmic Z (2004) Affect regulation. Handbook of self-regulation Research, theory and applications, Guilford Press, New York 40-61.

12. Whisman MA, Miller IW, Norman WH, Keitner GI (1991) Cognitive therapy with depressed inpatients: Specific effects on dysfunctional cognitions. Journal of Consulting and Clinical Psychology 59: 282-288.

13. Beck JS (1998) Complex cognitive therapy treatment for personality disorder patients. Bulletin of the Menninger Clinic 62: 170-194.

14. Ministry of Health, National HIVIAIDS Prevention and Control Office (2006) AIDS in department, ministry of health, Addis Ababa.

15. Ministry of Health (2004) AIDS in Ethiopia, fifth report: Disease prevention and control, Addis Ababa, Ethiopia.

16. Malindwa N (2003) Study on reproductive health and HIVIAIDS among persons with disabilities in Kampala, Katakwi and Raki Districts (Knowledge, attitudes and practices). Disabled Women's Network and Resource Organization, Uganda.

17. Lau JTF, Tsui HY (2005) Discriminatory attitudes towards people living with HIVIAIDS and associated factors: A population based study in the Chinese general population. Sex Transm Infect 81: 113-119.

18. United Nations/UNDP-SEAHIV/UNAIDS (2004) Mobilizing a response to HIV/ AIDS. Maritime industry.

19. Altun I (2004) Knowledge, attitudes and beliefs of maritime college students concerning HIVIAIDS. HIVIAIDS Rev 3: 51-56

20. Çetin ET (2000) HIVIAIDS'in Dünyadakidurumu (The situation of HIVIAIDS in the world). AIDS ým Bülteni 36: 8-10.

21. Izdebski Z, Malecka A (2003) Attitudes and opinions of youth concerning HIV AIDS problem. HIVIAIDS Rev 2: 115-122.

22. Brook U (1993) AIDS-related knowledge and attitude of high school students in Holon, Israel. J Trop Pediatr 39: 382-384. 